\title{
Ejercicios comparativos sobre la «locura» en el Chaco argentino
}

\section{Florencia Tola}

(iD) https://orcid.org/0000-0002-6777-4575

Universidad de Buenos Aires

Consejo Nacional de Investigaciones Científicas y Tecnológicas (CONICET)

tolatoba2015@gmail.com

RESUMEN

Este texto intentará llevar adelante un ejercicio de comparación entre las comparaciones efectuadas por mí y aquellas realizadas por mis interlocutores tobas (qom) del Chaco argentino, con miras a dilucidar las herramientas con las cuales ellos y yo las realizamos. Partiré de tres acontecimientos ocurridos durante mi trabajo de campo, realizado desde 1997 hasta el presente, que remiten al contexto que podríamos calificar como la «locura» y que refieren a cuestiones ontológicas. Los casos expuestos me permitirán mostrar el contraste explicitado por mis interlocutores entre los modos no indigenas (blancos) y qom de concebir la locura-el devenir-otro, y reflexionar sobre los desafios que implica concentrarse en el quid de la comparación desde el punto de vista de nuestros interlocutores indígenas.

Palabras clave: locura, Gran Chaco, chamanismo, ontología. 


\title{
Comparative exercises on «madness» in the Argentinean Chaco
}

\author{
ABSTRACT
}

This paper tries to carry out a comparative exercise between the comparisons made by me and those made by the Toba people (qom) of the Argentinean Chaco. I will try to elucidate the tools with which they and I made these comparisons possible. I will refer to three events that occurred during my fieldwork carried out from 1997 to the present. These cases are related to the context of that we may call as «madness», and that have ontological implications. The events show the contrasts explained by my indigenous interlocutors between a non indigenous and a qom way of conceiving madnessbecoming-other. These ethnographic cases will allow us to reflect upon the challenges involved in concentrating on the quid of the comparison from the Toba point of view.

Keywords: madness, Gran Chaco, shamanism, ontology. 


\section{INTRODUCCIÓN}

Este texto se basa en la revisión de tres situaciones transcurridas durante mi etnografía entre los tobas (qom) del Chaco argentino desde 1997 hasta el presente. La relación ininterrumpida con familias e individuos de cinco comunidades de la provincia de Formosa me permitió acompañar las transformaciones que fueron viviendo a lo largo de estos veinte años ${ }^{1}$. De hecho, las tres escenas que sintetizaré se han desenvuelto desde el comienzo de mi trabajo de campo hasta el día de hoy. Las vivencias de Juan, Pedro y José 2 , sus relaciones familiares, comunitarias, con los agentes del sistema de salud y con los sacerdotes católicos están asociadas, para los blancos, al universo de la patología mental y de la posesión y, para los tobas, a los matices de las relaciones humanas y no-humanas y a las inestabilidades propias de las personas compuestas y porosas ${ }^{3}$.

El objetivo de este texto no es brindar respuestas a los conflictos que surgen en el campo intercultural de la salud mental o del sincretismo religioso, ni tampoco clasificar las experiencias emocionales de mis interlocutores. Me propongo, más precisamente, adentrarme en uno de los terrenos de la práctica de la comparación

1 El Gran Chaco constituye una vasta llanura semiárida que se extiende sobre parte del norte de la Argentina, del este de Bolivia, el oeste de Paraguay y el sur de Brasil, a lo largo de un millón de kilómetros cuadrados. Esta región se halla delimitada por los ríos Paraná y Paraguay hacia el este, por la precordillera de los Andes hacia el oeste, por los llanos de Chiquitos y la meseta del Mato Grosso hacia el norte y por la cuenca del río Salado hacia el sur. Los tobas pertenecen - junto con los pilagás y los mocovíes - a la familia lingüística Guaycurú y se autodenominan qom.

2 Utilizo pseudónimos en los tres casos para preservar la identidad de mis interlocutores.

3 En consonancia con numerosas etnografías amerindias de los últimos treinta años, en trabajos previos me dediqué a dar cuenta del modo en que la persona es constituida entre los qom con límites corporales porosos y compuesta socialmente, desde su gestación hasta la muerte, a través de la circulación de elementos, sustancias, nombres provenientes de humanos, animales, vivos, muertos, parientes y chamanes. Sobre el tema, ver Tola $(2009,2012,2013)$. 
—o de la equivocación en el sentido de Eduardo Viveiros de Castro (2004)-, incluso de la «casi fatal equivocación», tal como expresa Cristobal Bonelli (2013, p. 408). En efecto, si toda traducción conlleva riesgos, y si los tres casos refieren a situaciones límites entre la salud y la enfermedad, la vida y la muerte, es preciso intentar controlar la equivocación a los fines de evitar algunos riesgos fatales que dichos equívocos podrían acarrear.

Es preciso reconocer que, si la antropología consistiera, según varios autores (Wagner 1975, Viveiros de Castro 2004), en la comparación de antropologías diferentes, cabe preguntarse ¿cómo comparamos antropologías sin subsumir las otras antropologías a nuestros propios términos? El terreno de la comparación de antropologías está atravesado, sin lugar a dudas, por equívocos en los que es factible incurrir si se presupone que nos encontramos ante sinónimos transculturales. Si en las traducciones nos hallamos ante dos palabras de dos lenguas diferentes que refieren a una misma cosa - ya que hay un mundo objetivo que es garante de dicha conexión ( $\log$ y perro) - , tal como desarrolla Viveiros de Castro $(2004 ; 2014)$, en la traducción de conceptos de dos culturas diferentes esta suposición nos conduce a equivocaciones debidas a la existencia de «homónimos engañosos» (Viveiros de Castro, 2004; 2014). Términos homónimos no remiten siempre a realidades homónimas. En la Amazonia perspectivista, la equivocación es controlada, ya que los diversos tipos de seres saben que las semejanzas aparentes encubren realidades diferentes: humanos y pecaríes pueden llamar «pez» a lo mismo, pero para unos ese término refiere a un pez y para otros a la sangre.

En nuestro caso, como mostraremos, dejar morir de hambre y sed a una madre, dejar de hablar con los parientes para solo comunicarse con los espíritus y vivir una juventud al borde del suicidio por las perturbaciones causadas por las «presencias espirituales» son experiencias que, aunque dispares, se anclan en conceptos de cuerpo, persona, salud y relación distintos - y bien distantes- del sentido que el multiculturalismo, la biomedicina y el catolicismo les atribuyen. Las lecturas y tratamientos diferenciales que los qom y los blancos (a través de la mirada de los qom) efectúan de las situaciones vividas y relatadas les permiten enfatizar sus diferencias e inventar, en este proceso, su cultura (Wagner 1975). Es en la controvertida zona de traducciones cruzadas de situaciones que oscilan entre la vida y la muerte, la socialidad y la individuación, en donde se ubicará mi lectura de estas experiencias vitales. 


\section{LECTURAS CRUZADAS SOBRE LA VENGANZA, LA MUERTE Y EL CUERPO}

Cuando Juan tenía trece años, murió su madre Agustina. Según el relato de Juan, que hoy tiene más de sesenta, en aquel momento llegó al funeral un pariente lejano. Luego de conversar con él y con sus hermanos, este pariente emprendió «la contra» en el cuerpo de Agustina. Juan recuerda que al cuerpo de su madre se le hicieron diversas acciones que aspiraban a que la «venganza» actuara en su atacante. Al poco tiempo, una prima clasificatoria de Agustina comenzó a hablar sola, a reír y a repetir incesantemente el nombre de su prima fallecida. Según Juan, la hija de esta anciana expresó: «Esta vieja mala es la asesina...». De hecho, para ella su madre manifestaba los síntomas de 'alaxaic. Movida por el enojo y el temor, la mujer pidió a sus hijos que alejasen a la anciana de la casa y que la ubicasen debajo de un árbol, a cincuenta metros del hogar. Allí quedó su madre, sola, sin comida ni bebida. «No le den de comer, no le den de beber», reiteró la hija de la mujer a sus propios hijos. Allí, al poco tiempo, la anciana murió de hambre y sed s. $^{4}$

Desde los comienzos de mi trabajo de campo en un barrio periurbano de la ciudad de Formosa, mis interlocutores me hablaban casi diariamente de las acciones emprendidas por curanderos y brujas. Ambos términos son, sin duda, consecuencia de la interacción colonial que los pueblos indígenas chaqueños han entablado con

4 En consonancia con lo vivido por sus antepasados, Juan acaba de perder a su único hijo de cuarenta años a quien los doctores le diagnosticaron diabetes. Sin embargo, Juan sabe por medio de un chamán que «cinco mujeres hicieron la muerte» de su hijo. En el funeral, Juan recibió la visita de un pariente lejano que le ofreció hacerle «la contra» al cuerpo de su hijo para que las mujeres sean desenmascaradas. Esta situación, vivida más de cien años después, nos permite mostrar la vigencia de una práctica muy antigua que ya fuera referida por diversos etnógrafos de la región. Miller, por ejemplo, refiriéndose a la técnica de la venganza, refiere: «Una técnica de contra-daño comprende la recolección de la savia del algarrobo [...] tres pequeños frutos [...] de la planta de caraguaté, y el agujero de un hormiguero [...] Los tres elementos deben ser mezclados, hervidos, y dados de comer a la persona dañada, justo antes de la muerte. El moribundo debe ser forzado, si es necesario, a tomar el brebaje, con lo cual devolverá el daño al que lo causó, asegurando su muerte» (1979, p. 44-45). Encontramos además semejanzas entre estas técnicas y aquellas referidas para otros grupos chaqueños. Si los abipones sospechaban que la muerte de un pariente se debía a un acto brujeril, ellos «removed and boiled the deceased's heart and tongue, and threw them to the dogs in order to harm the unknown sorcerer» (Métraux 1963, p. 329). Los mocovíes recubrían el cuerpo del difunto y lo quemaban. Gracias al chamán, se evitaba que el brujo identificado escapara a la muerte (ibid., referencia de Paucke de 1870, p. 355). Los lengua mutilaban el cuerpo del difunto para eliminar así la fuente del mal (ibid.). Si los ashluslay suponían que una muerte se debía a brujería, «they perform a similar rite to incide the victim to kill his murderer» (ibid.). 
diversos agentes de la conquista, la colonización de sus territorios y la misionalización emprendidas desde hace ya varios siglos ${ }^{5}$. En toba, los curanderos son llamados pi 'oxonaq, término que refiere a uno de los pilares de la acción terapéutica: ellos son «expertos en la succión» ${ }^{6}$. Succionando, soplando y pronunciando plegarias, los pi'oxonaq curan a quien fue atacado por otro pi'oxonaq mediante sus «misiles», «balas indias» o «bichos» (términos para designar el lexema toba piguishic ${ }^{7}$ ). El acto terapéutico devuelve el ataque al agresor esperando causar su muerte. Las conaxanaxae son, en cambio, las mujeres que los qom identifican con las «brujas». Ellas son, más precisamente, «agarradoras» ${ }^{8}$ de extensiones corporales (cabello, ropa) o de componentes exteriorizables de la víctima (alma, nombre, calor, sombra). Una vez en su poder, ellas fusionan dichos elementos con entidades consideradas non sanctas (sapos, víboras, huesos de muertos) y esta mezcla es la que causa la muerte, casi inevitable, de la persona capturada.

Además de estas dos figuras centrales en la cosmopolítica toba, en los últimos años de mi trabajo de campo los tobas me refirieron sobre otros especialistas encargados de realizar «la contra» o venganza. Los 'enaxanaxaic — para quienes no me proporcionaron traducción al castellano- son aquellas personas que, sin haber recibido poder no-humano ni ser necesariamente curanderos, ofrecen su servicio a parientes o familias allegadas que acaban de perder a un ser querido9. El término 'enaxanaxaic se compone de la raíz del verbo «dañar con brujería/ven-

5 En 1884 se inició la campaña militar conocida como la Conquista del Desierto del Chaco destinada a «pacificar» a los indígenas chaqueños. Dicha conquista se prolongó hasta 1911. A partir de entonces, la estrategia de colonización del territorio conquistado fue la de reforzar la línea de fortines, las expediciones punitivas, las misiones religiosas y la distribución de la tierra conquistada a los colonos.

6 Pi'oxonaq: del verbo pi'oxon-: «chupar» o «lamer», -aq: sufijo que indica «el que es experto en».

7 Piguishic se asocia a la idea de 'poder' (-pinsh-). A esta base se le agrega el sufijo nominalizador -ec/ic que indica 'lo que acompaña', 'lo que pertenece a'). Según el diccionario de Buckwalter, napiishaxanaxanec es «su curandero poderoso», napiishic o napinshic, napinshaxac y napinshin son los términos que expresan «poder», «poder secreto para curar», «poder secreto». La enfermedad se asocia a la base de poder también (napijna, napijnataxac).

8 Conaxanaxae: del verbo -cona-: «agarrar», el sufijo -xanaxai remite al que realiza la acción del verbo.

9 Sobre el tema de la venganza y la brujería, en 2019 publiqué un artículo en Social Analysis en el cual me centro en la metafísica qom de la relación y analizo, para ello, en la práctica de la brujería y la venganza realizada en el cuerpo del moribundo. El objetivo de ese artículo fue mostrar que en un universo en el que todo comunica, todo impregna y es afectado, la vida social qom pareciera ser el producto de la alternancia entre una relacionalidad excesiva y la búsqueda de fisuras en este magma de relaciones que oscilan entre la compasión y la envidiamezquindad. En este artículo retomo, en el primer caso analizado, algunos datos analizados 
gar» y también del verbo «burlarse» $\left(-i^{\prime} e n\right)^{10}$. Este especialista es quien propone a los parientes del fallecido «remediar» — en el sentido de dar una solución a un daño-, «hacer la contra» — en el sentido de contratacar - o «curar al muerto» —no en el sentido terapéutico, sino de efectuar una manipulación especial en su cuerpo - . Todas estas expresiones contienen la idea implícita de que, por medio de un remedio, de un contrataque o de una transformación corporal se desenmascarará al culpable y se lo matará ${ }^{11}$.

Más que interesarme por lecturas abstractas y generales de fenómenos como la brujería y el chamanismo, proponiendo ya sea un acercamiento simbólico de ellos, ya sea un análisis de las representaciones de estas prácticas en la escala de la modernidad y del malestar que ellas estarían canalizando ante el individualismo creciente y el capitalismo, a lo largo de mi trabajo de campo el detalle de situaciones locales, los conflictos latentes en las relaciones, el entramado fino de los vínculos parentales en los que afloran las acusaciones y en los que se produce el ataque y el contrataque se fueron constituyendo como los ejes rectores de mi perspectiva sobre el tema. El sistema de ataques y contrataques, de daños y contras se ancla, por un lado, en una ideología guerrera y predatoria de un pueblo cazador que, hasta hace poco más de un siglo, emprendía guerras interétnicas y toma de cautivos y scalps de sus enemigos, y por otro, se entrelaza con esferas de la socialidad toba contemporánea ${ }^{12}$. Las referencias a estos temas emergen hoy no solo para hablar de las formas cosmopolíticas de curar y vengar, sino para hablar de la política, de los líderes tobas y de sus relaciones con los blancos, de la diferencia entre la violencia física y frontal a la que suelen recurrir sus vecinos criollos y las formas qom «escondidas» que se activan para resolver conflictos intracomunitarios e interétnicos.

Desde esta óptica, voy a intentar sintetizar la interacción entre atacantes, moribundos, vengadores y muertos intentando no interpretar las interacciones a partir de definiciones conceptuales de un fenómeno que escapa a la explicación

en el artículo publicado en Social Analysis pero con el objetivo de abordar las lecturas diferenciales sobre la locura.

10 Agradezco a Paola Cúneo el análisis de este término en lengua toba.

11 Para un análisis en profundidad de la «venganza» o contrataque entre los qom, ver Tola (2019).

12 Sobre la toma de scalps, ver Nordenskiold (1912), Karsten (1932), Palavecino (1933), Métraux (1937) y Lozano (1941). Las primeras fuentes anteriores a la «pacificación» y otras ulteriores refieren al carácter belicoso de los indígenas chaqueños, así como a la toma recíproca de scalps y de cautivos entre enemigos preferenciales (Sterpin 1993, pp. 36, 40). Las guerras entre pares de enemigos étnicos o facciones estaban motivadas, muchas veces, por la venganza (Sterpin 1993 , p. 58, nota 12). 
totalizadora. En la agonía, algunas personas tienen una visión de su agresor y esto facilita la «contra» o venganza que realizará un chamán o una bruja con sus técnicas y conocimientos propios. Pero en los casos en los que la visión no ocurre, los parientes pueden optar por emprender, con el 'enaxanaxaic, acciones en el cuerpo del moribundo que se espera causen el ataque correlativo en el agresor. El término qai'ỹen refiere a la acción de «la contra» o venganza y se construye sobre la misma base verbal (-i'en) del término 'enaxanaxaic. La contra requiere, para su eficacia, que el cuerpo de la víctima esté caliente, ya que el calor indica que el atacante (su nqui'i o sus nattac — compañeros no-humanos-) está aún adentro de su víctima. Esta acción busca una transformación corporal del moribundo en manos de su vengador, quien le rompe los huesos, le corta la piel, le introduce objetos dañinos, entre otras cosas. Esta transformación incidirá en el destino del muerto y del agresor en tanto personas indivisas, claramente dividuales (Strathern 1988). Es decir, si el cuerpo está caliente, el atacante y la víctima están unidos y la alteración del cuerpo de uno conlleva la alteración del cuerpo del otro en tiempos diferidos.

Existen algunas situaciones en las que los parientes deciden no vengar al muerto y acá llegamos, finalmente, al caso de la primera escena y al sentido mismo del término 'alaxaic. Poco tiempo antes de morir, una persona puede volverse, a los ojos de sus parientes, 'alaxaic, como nos muestra nuestro caso. Fenomenológicamente, 'alaxaic es quien nombra a muertos, quien tiene visiones de personas que los otros vivos no ven y quien se queja y sufre por dichas visiones de muertos. Estos signos externos conducen a los doctores blancos a diagnosticar a estas personas como «dementes», enfermos mentales que sufren «alucinaciones» $\mathrm{y}$ «delirios», tal como los qom me expresaron. Sin embargo, los parientes cercanos saben (y no creen) que esto no es «locura». Lejos de ser alucinaciones o delirios propios de un estado de demencia, las visiones que perturban al 'alaxai son las personas asesinadas por él. El 'alaxaic se torna, para sus parientes, en un brujo-asesino desenmascarado por las visiones, que comenzó a transitar el proceso gradual de la muerte, ya sea porque sus víctimas lo están llevando con ellas, ya sea porque la familia decide no sostener con él más interacciones conviviales. Con él se opta por destejer la relacionalidad que el proceso mismo del parentesco se había encargado de hilar lenta y gradualmente.

En estos casos, los ataques pasados leídos retrospectivamente, la venganza en el cuerpo y la presencia de los muertos ante su victimario constituyen el reverso oscuro del parentesco y obran quebrando la red de relaciones interpersonales finamente producidas. Finamente producidas, aunque tanto esta como otras 
ejemplificaciones de «brujería familiar» ( $c f$. Bonhomme para África subsahariana) atestiguan que la «[...] transparencia absoluta en las relaciones interpersonales, incluidas $[\ldots]$ las situaciones de familiaridad máxima como es el parentesco», resulta imposible (Bonhomme 2009: 90).

Si lo que la anciana expresaba antes de ser abandonada por sus parientes hasta morir eran delirios y alucinaciones que, para el discurso biomédico psiquiátrico, acompañan los cuadros de demencia, la manera de actuar de su hija y nietos indicaría una profunda crueldad en el seno del parentesco y la ausencia de compasión ${ }^{13}$. Sin embargo, ambas actitudes son, por un lado, contrarias a la manera en que los qom viven y conciben el parentesco y, por el otro, constituyen algunos de los ejes centrales de la diferenciación con los blancos. Ante el abandono de los ancianos blancos en los geriátricos, una anciana toba me expresaba: «Es tristísimo ver a los ancianos de los blancos... ¿qué pasaría a la inversa: si al nacer los padres mandaran a sus hijos a que los críen otros?». Lo que me interesa enfatizar es que, lejos de expresar, para los qom, algún tipo de patología, las personas que devienen 'alaxaic están expresando la consecuencia de sus acciones pasadas, ocultas, y mostrando que la persona qom no es una singularidad sino un entramado de relaciones, una entidad compuesta, porosa y descomponible. Así como el moribundo, para ser vengado, tiene que tener en su interior al espíritu del atacante, cuando se es 'alaxaic se está en un proceso de transformación hasta morir, a raíz de la presencia de los muertos por él asesinados. Víctima y victimario se confunden y, alternadamente y dependiendo del punto de vista, se es uno o se es otro.

Al hacer la «contra» a un moribundo, el atacante deviene 'alaxaic porque sus acciones «se le vuelven en contra». Esta explicación qom expresa que el abandono de la anciana por su hija tras observar que su madre comenzó a nombrar a un muerto no es una acción moralmente condenada. De hecho, más que un abandono es un intento explícito de antivenganza, es decir, de no vengar a la anciana el día en que muera, pues ella se «manifestó» como una bruja y si se la vengara, a los vivos les esperaría un contrataque posterior. De los 'alaxaic los parientes ansían distanciarse para no morir en una «guerra» que es «invisible» para los blancos, pero que para los qom está hecha de ataques y contrataques con «bichos», «balas», «saetas chamánicas» o con cuerpos alterados por la «contra».

13 La compasión es una de las modalidades relacionales centrales en la socialidad qom. Más que una emoción individual, la compasión es un valor moral que se sitúa en el corazón mismo de la socialidad qom. 
Estas ofensivas y contraofensivas se suceden a lo largo de las generaciones y ponen en riesgo diferidamente a quienes no opten por desvincularse de quien ha sido desenmascarado con sus visiones de muertos.

En suma, el abandono y la violencia sin compasión, los qom los sitúan en otro lado, en otras relaciones: en las relaciones intergeneracionales de los blancos y en el geriátrico. Este lugar al que los blancos envían a sus padres es equiparado con su situación reversa, es decir, con el abandono de un recién nacido para que sea criado por otra familia... Sin embargo, visto desde otro ángulo, el abandono de un hijo al nacer entendido como el equivalente al de un anciano antes de morir no es un gesto exento de complejidades y matices, para los qom. En las comunidades tobas es habitual la circulación de niños, se practicaban infanticidios y se practican, clandestinamente, abortos, como en muchos otros pueblos de tradición cazadora-recolectora. Sin embargo, hoy se oponen fervientemente a estas prácticas consideradas salvajes y deshumanas, y en su crítica al abandono de ancianos por los blancos, condenan el desprendimiento de bebés — nacidos o por nacer-.

Por la década de 1960, Georges Devereux anticipaba una propuesta simetrizadora al expresar que «las intuiciones» de nuestros interlocutores no son tan solo objeto de nuestros análisis, sino «instrumentos conceptuales» que en no pocos casos se convirtieron en categorías analíticas de las ciencias del comportamiento ${ }^{14}$. Asimismo, expresaba que «las divagaciones de las metafísicas», al igual que «las racionalizaciones de un neurótico, los fantasmas de un psicótico, las divagaciones de los mitos, de las teologías», si bien no contienen «bajo una forma inmediatamente utilizable nuevas ideas sobre la naturaleza humana, ni nuevos métodos en el estudio del comportamiento», contienen efectivamente «signos indicadores oscuros de nuevos problemas y de nuevas soluciones...» (1980[1967], p. 183). La escena sobre la anciana 'alaxaic y las lecturas cruzadas que me refirieron mis interlocutores sitúan la comparación en distintos niveles $y$, a través de ella, plantean interrogantes y respuestas posibles a las tensiones propias de las relaciones entre los diversos existentes (humanos y no-humanos, vivos y muertos, qom y blancos, ancianos y jóvenes) y a sus modos de resolución.

Mirados desde la perspectiva qom, los ataques chamánicos y brujeriles, las visiones de moribundos y de 'alaxaic, la venganza en el cuerpo y la antivenganza de los parientes son modos tanto de crear socialidad como de producir indivi-

14 «Se puede retomar a veces directamente las intuiciones de los primitivos e incluso de los pacientes, y utilizarlas al mismo tiempo como datos brutos y como instrumentos conceptuales» (Devereux 1980[1967], p. 181, traducción nuestra). 
duación, de establecer una comunicación o de impedirla, y de incidir, activa e intencionalmente, en una amplia variedad de personas evitando la acción frontal, explicita y sin rodeos, consideradas expresiones de una ausencia de autocontrol. Estos modos absolutamente normales y no patológicos para ellos contrastan con las modalidades en que los doctores, los maestros, los vecinos, los políticos, los misioneros y los antropólogos, entre otros, evalúan, sopesan, hipotetizan, buscan explicaciones e interpretan los supuestos mismos fenómenos. Supuestos mismos fenómenos si sostenemos la monarquía del naturalismo y la existencia de una naturaleza -única y universal-y muchas representaciones. Para profundizar en esta reflexión nos adentraremos ahora en la segunda escena.

\section{LOS LÍMITES DE LA CIENCIA: NO VER, NO CREER, NO SABER}

Pedro tenía diecisiete años cuando, de regreso a su casa, algo cambió el rumbo de su vida hasta el día de hoy, que cumplió veintitrés. Pasó de ser un estudiante de secundario, alegre, locuaz y sociable a ser un hombre solitario y silencioso que pasa sus días en la casa de sus padres y hermanos, asistido por su madre, sin pronunciar palabra con ellos y sin poder emprender ninguna acción por sí mismo. A veces, sus hermanas refieren que lo escuchan conversar con espíritus. A los pocos días de esa noche, Pedro narró a sus padres lo que le pasó: mientras bordeaba una represa se le apareció un pel'ec o «habitante de la noche» y su presencia lo atormentó. A partir de ese momento no pudo volver a dormir tranquilo, tiene miedo, llora, grita y conversa solamente con espíritus.

«Las ciencias naturales tienen su límite, hay cosas que no pueden explicar», me expresó, Susana, la mamá de Pedro, con quien mantengo un vínculo familiar desde hace muchos años. Intentaba con esto trasmitirme su frustración debida a las sucesivas consultas a clínicos, psiquiatras y neurólogos y a los dispares diagnósticos que le pronunciaron sobre la 'enfermedad' de su hijo. El primero fue «síndrome de abstinencia y estado alucinatorio» ya que Pedro había contado a los doctores que esa noche había fumado pasta base de cocaína. Fue medicado para eso, pero su problema persistió y el padre lo llevó nuevamente al hospital. Luego de algunos estudios y de escuchar el relato de los episodios sucedidos, otros doctores diagnosticaron «psicosis» y lo medicaron con medicación antipsicótica que dejó a Pedro en un estado peor que su malestar (dormía todo el día, no reaccionaba ante nada, «parecía drogado»). El padre lo llevó de nuevo al médico y el último diagnóstico que recibió fue «esquizofrenia». Ante tantas 
variaciones en el diagnóstico y la medicación, Susana decidió que su hijo no consultaría más a los especialistas médicos y me dijo: «Si les contamos lo que le pasó a Pedro, si contamos lo que verdaderamente le pasó, nos van a tratar de locos a nosotros y hasta quizás nos encierren. Por no ir en contra de los doctores, los escuchamos y no decimos nada porque no ven, no creen, no saben. Na qom sabe. Cuando mejoró un poco los doctores decían 'milagro' o 'sobrenatural' porque en realidad no saben».

Retomo para este caso el concepto ontological disorders de Cristobal Bonelli (2014), quien reflexiona sobre las situaciones controvertidas que determinadas «cosas médicas» producen (píldoras para dormir, en su caso entre los pehuenches chilenos). Estas situaciones son leídas por él en términos ontológicos en el sentido de que ellas activan experiencias, existentes, mundos y relaciones cuyos significados son diferentes para los indígenas y para quienes no lo son. En su análisis, la equivocación atraviesa una interacción controvertida (una mujer que toma píldoras para dormir a raíz de experiencias nocturnas que parecen pesadillas) y «los efectos de la 'cosa médica' alteran un mundo, no solo una 'mente'» (2014, p. 411). En nuestro caso, el encuentro de Pedro con un pele'c generó en él un estado que numerosos tobas han experimentado. No es el primer qom que encuentra un ser nocturno. Ahora bien, ante los efectos de este encuentro los padres intentaron buscar una solución 'blanca'. Este movimiento es el inicio de ontological disorders en Pedro, en sus padres e, incluso, en mí. Ante la visión de Pedro incapaz de actuar por sí mismo, tras ver que los padres intentaban encontrar una respuesta en la biomedicina, ofrecí mi colaboración en las consultas a neurólogos y psiquiatras. Sin embargo, me atravesaban dos tipos de dudas: por un lado, ¿por qué no intentaban resolver este encuentro perturbador del mismo modo en que otros qom lo hacen? Y, por otro, ¿por qué, en mi caso, no estimular a que realicen dicho recorrido, en vez de proponer mi ayuda para la búsqueda de una solución biomédica?

La pregunta que me hacía al respecto era si mi apoyo a que un neurólogo lo revisara no tenía relación con mi substrato naturalista que sostiene la existencia de un cuerpo universal y que contiene la idea implícita de que, si hay una base neurológica en ciertos trastornos psiquiátricos, estos bien podrían ser tratados de la misma manera en que lo son entre los blancos, más allá de cualquier interpretación cultural. Este argumento equívoco es sobre el que urge reflexionar si pensamos que sus supuestos ontológicos atraviesan también las respuestas dadas por los médicos. Los doctores que (mal)diagnosticaron a Pedro, quienes no se preocuparon por tratar el caso desde la interculturalidad, respondieron movidos 
por una de las premisas del multiculturalismo según la cual «el cuerpo hace las mismas cosas independientemente de su localización» (Bonelli 2014, p. 412), o del naturalismo, según el cual los humanos compartimos una misma naturaleza (el cuerpo y sus posibles trastornos patológicos).

El problema en el caso de Pedro es que, por un lado, los doctores del hospital público de una de las provincias más relegadas del país no supieron diagnosticarlo correctamente y darle la medicación acorde (hicieron, de hecho, diagnósticos muy disímiles y recetaron remedios con efectos secundarios muy severos). Por eso, en palabras de su madre, ellos no saben, porque efectivamente no supieron tratar este caso. Por otro lado, ante etiologías tan diferentes para la biomedicina y para los qom, la respuesta errada de los doctores a los ojos de los qom no se basa únicamente en el no saber. Ella se sustenta fundamentalmente en el no ver y no creer. Para los qom, fue un ser no-humano (actante, intencional y sintiente) quien intervino en la vida de Pedro y, a partir de ese momento, este se encuentra compuesto por esta persona no-humana. Pero esto los doctores no ven y no creen.

El conflicto se ubica en un plano ontológico, no solo - ni fundamentalmenteepistemológico. Para Susana, la causa verdadera debe, entonces, ser ocultada por temor a ser diagnosticados ellos como «locos» y encerrados. Cuando me refería su consulta a los especialistas, sus silencios y su firme decisión al abandono de todo tratamiento, estaba mostrándome — una vez más - su esfuerzo superlativo de traducción de mundos, su control lúcido de la equivocación y su firme certeza de que, más que una entidad biológica susceptible de ser afectada por los mismos problemas que el cuerpo de cualquier ser humano, el cuerpo qom no existe por fuera de un complejo entramado de relaciones humanas-más-que-humanas.

Hace pocos años, luego de los fallidos diagnósticos médicos, los padres de Pedro lo introdujeron en la Iglesia evangélica toba en la que congregan y decidieron que su hijo fuese curado con oración colectiva, que tampoco hizo efecto (según su madre, quienes oraban le temían a su hijo) ${ }^{15}$. Este año, finalmente, el episodio inicial del trastorno es resignificado a la luz de lo narrado por el tío paterno de Pedro: el problema de este fue un encuentro no deseado con un lobisón

15 A mediados del siglo XIX, en el Gran Chaco se llevaron adelante — aunque sin éxito- los primeros intentos misioneros protestantes por la South American Missionary Society. En Argentina, en la década de 1930, llegaron misioneros británicos que se establecieron en la ciudad de Formosa y fundaron entre los toba de la zona central de Chaco la misión Emmanuel. En la actualidad, la mayoría de las comunidades tobas de Chaco y Formosa poseen diversas iglesias protestantes y pastores que predican en lengua toba. Sobre el evangelismo toba, $c f$. Miller (1979), Wright (1983, 2002), Ceriani Cernadas (2005, 2011, 2017). 
(hombre-lobo, para la tradición europea) ${ }^{16}$. Cuando el tío paterno era joven tuvo, según narró, el mismo problema que Pedro. Una entidad mitad perro y mitad humana pasó por entre sus piernas y, a partir de ahí, se comenzó a comportar como dicho ser. Este trastorno solo pudo resolverse cuando el tío se lo transfirió a otra persona, tal como suele ocurrir.

Ahora bien, luego de varios años de comenzado el trastorno y de asistir a las diversas interpretaciones médicas y qom, no dejo de preguntarme: ¿por qué, con el paso del tiempo, fue esta nueva lectura de la causa del trastorno la que prevaleció ante las otras? ¿Por qué la figura del lobisón es «buena para pensar»? ¿Sobre qué permite hablar el lobisón y no el pele'c o ser de la noche? Encuentro por el momento dos respuestas posibles: el lobisón moviliza, más que el escurridizo «ser nocturno», representaciones colectivas sobre las relaciones interétnicas, por un lado, y alternativas de reversibilidad, por el otro. Si se tratara de un pel'ec posiblemente el destino chamánico sería la alternativa inevitable de Pedro, algo que su familia evangélica al día de hoy no admitiría.

Por último, la reflexión y la posición de Susana ante los avatares de la vida de su hijo y los desentendimientos con los trabajadores de la salud estatal pusieron al descubierto tanto la rigidez de la biomedicina y su fe en los efectos universales de las drogas, como el entrenamiento de esta madre toba en el ejercicio obligado de la comparación. Su perspectiva, nuestros diálogos y mis preocupaciones me reconfirmaron que en la «antropología reversa» de Susana su no ven, no creen, no saben es equivalente a mi búsqueda de soluciones con un trasfondo naturalista. La diferencia es que si yo insistiera en que Pedro fuese tratado por especialistas blancos y expresara argumentos para ello, yo no temería que los qom pudieran encerrarme bajo algún tipo de argumento que condena una lectura diferente de un fenómeno... simplemente, me escucharían pero sabrían que estoy equivocada.

\section{ENTRE UN CASO CLÍNICO, LA INICIACIÓN CHAMÁNICA Y LA FABRICACIÓN DE UN MUNDO HABITABLE}

Para concluir nos dedicaremos a continuación a la última escena que presenta una resolución alternativa a un desorden ontológico semejante al anterior. José es uno de los hijos de un reconocido chamán que falleció hace casi veinte años. Mientras su padre vivía, José lo asistió incansablemente, ya que el chamán padecía de una enfermedad respiratoria. A su vez, su padre lo instruía acerca del poder

\footnotetext{
16 Sobre el tema, ver Medrano (2018).
} 
que él detentaba y de los existentes que lo acompañaban. Todo indicaba que José sería el heredero del poder chamánico de su padre cuando este muriese. Durante su infancia y los años en que José asistía a la escuela secundaria, él vivió varios episodios que me iba relatando. Qasorot (ser del monte), pele'c (habitante de la noche), espíritus de muertos, ñoxoic (el perro sarnoso) y el dueño de la luna se le aparecieron desde que era niño. Por las noches, durante años, José no dormía, ya que estos y otros seres aparecían para interactuar con él: una cabeza de cabra, un cuerno de cabra sin ojos, dos dedos con bello, una oreja con un hilo colgando, una cara sin cuerpo. Hoy, casi diez años después de estas vivencias, José vive con una mujer, vende leña y no se dedica a curar. «Ahora me dedico a vivir, Florencia», me dijo hace pocos días en una conversación telefónica, «mi mundo ya no es lo que era antes». Sin embargo, sus capacidades y percepciones no desaparecieron, continuó: «A veces sueño con esas presencias y cuando estoy cerca de una mujer la huelo y me doy cuenta de si está embarazada, si está con ganas de estar con un hombre y huelo también su leche materna».

El caso de José es, sin duda, difícil de relatar por las complejidades de los sucesos que ha vivido durante estos veinte años y por el hecho de que sostengo con él una amistad de gran complicidad en la cual me ha confiado algunas de sus vivencias más íntimas. Referiré tan solo algunos episodios de la vida de José que, a la luz del chamanismo chaqueño, podrían ser leídos como etapas de un proceso de iniciación. Sin embargo, José no siguió el camino de la curación. A pesar de eso, sus relatos actuales, sus sueños y sus percepciones permiten poner en duda que el chamanismo pueda limitarse, en el Chaco, a la práctica terapéutica. Esta última escena será relatada en primera persona, a partir de sus historias que me refirió durante años y que contienen recuerdos de su nacimiento, del abandono de sus padres, de sus antepasados humanos y no-humanos y de sus «presencias espirituales». A su vez, en su narrativa hay intentos permanentes de encontrar las causas de su trastorno y de explicar el modo en que se produjo la curación gracias a los mismos seres no-humanos que lo afectaron y a sacerdotes católicos que lo exorcizaron.

Yo me acuerdo cuando nací. Al nacer no hice problema, no sufrió mi mamá. No había doctor, me cortaron el cordón con un cuchillo bien filoso, tuve miedo. Yo sentí que mi mamá no sintió dolor, yo nací llorando porque sabía que cuando nacía iba a sufrir, que algo me iba a tener como un hijo más de esta tierra, porque yo siempre he sentido estas molestias. Yo sentía que alguien me estaba mirando cuando nací. Cuando era bebé tenía sarna en el cuerpo. Todo mi cuerpo se pudrió. Yo sufría, sentía que estaba sufriendo porque sentía dolor. 
Pasaron algunos meses de su nacimiento y, a raíz de una separación temporaria, sus padres lo abandonaron en el monte. Allí fue atormentado por diversos seres y fue también protegido por la luna:

Apareció mi tatarabuelo, con un canto, una máscara, era Martini. Tiene canto para curar cualquier enfermedad. Mi papá canta esa canción. Cuando era bebé y estaba en el monte, escuché por primera vez esa canción. Había un pájaro de oro que viene volando hasta el fuego donde estoy. Es como un águila y ese es Martini, mi ancestro. El pájaro era Martini y le dio el poder a mi abuelo y a todos mis ancestros. Mi papá conoce al poderoso, a ese pájaro de oro que viene del cielo. No es humano, si es humano todos lo verían, yo lo veo en sueños.

Luego fue rescatado por su abuela materna: «Me dejó en lo de una tía que me crió. Tomé leche de cabra para no desnutrirme. Era sarnoso. A lo mejor ya estaba previsto todo esto: cuando mi mamá estaba embarazada le tocó la panza un personaje, un pele 'c'». José encuentra en el contacto de su madre embarazada con el pel'ec una posible causa de sus iniciales malestares. De hecho, las mujeres embarazadas deben evitar que estos habitantes nocturnos las toquen o entren en su cuerpo ya que, de hacerlo, podrían alterar el aspecto físico y el comportamiento del niño por nacer. Este encuentro intrauterino pudo determinar, según su lectura, sus trastornos y la percepción de entidades que otras personas no ven. Por las noches, José (su espíritu) recorría el barrio y tenía encuentros vividos que incluso le hicieron suponer que estaba soñando, aunque luego se dio cuenta de que esas interacciones eran reales (para nosotros eran sueños).

Cuando duermo veo que mi espíritu se levanta y pasea por el patio de mi casa, pero nunca frente a mi papá. Doy toda la vuelta a la casa, menos donde está mi papá, porque donde está él parece que hay un vidrio que lo protege. Salgo por el costado a pasear. Vuelo, siento que vuelo y miro el barrio. La otra noche me levanté y pensé que estaba soñando, me fui de paseo y me encontré al chico que silba. Estaba desnudito. Primero veía que venía alguien del pastizal silbando, cuando llega hasta el patio de mi casa, va por la vivienda y quiere pasar allá, pero está mi papá y a él lo protegen. Mira para todos los costados y si ve que no está nadie viene a esta casita y acá me molesta porque no hay poder. A veces cuando él me mira, yo me escondo detrás de una planta y cuando salgo lo quiero agarrar y quiero jugar, pero él no quería jugar, se asusta y raja de vuelta al pasto. Al marcharse los pastos se cierran. Él viene de havit, de donde vienen los muertos, me parece que es él quien lleva las almas de los muertos. Es un nenito chiquitito muy lindo. Yo quería jugar con él. Le quería preguntar qué es lo que busca, pero sentía cariño y miedo a la 
vez, porque yo sé que algo está buscando, parece la muerte, se lleva las almas que quieren irse... Yo he tenido siempre alguna presencia espiritual.

El contacto de pele'c con su madre no es la única causa que José encuentra para dar cuenta de sus visiones y, su transitar por la vigilia y el sueño de modo indistinto continuó en su etapa escolar. Una vez que se fue al monte en busca de leña se quedó dormido al pie de un árbol:

Después de eso me enfermé porque me aparecieron estos seres. Cuando me desperté me olvidé del hacha y del machete y me fui caminando sin sentido. Casi me volví loco porque no sabía si estaba dormido o despierto. Sentía que mi mundo casi no existía. Me parece triste cuando yo cuento esto. Yo me enfermé por ese nonaxale'c, del campo. Me agarró una inconsciencia, mi problema psicológico. Casi me volví loco, mi mundo no tenía sentido, tenía dolor de cabeza, sentía que mi cabeza se hinchaba y tenía mucho dolor y me quería suicidar. Tenía muchos problemas, caminaba por cualquier lado, hasta me fui lejos, no sabía a dónde llegar. Mi mundo ya no tenía sentido. Mi ropa se arruinó, me la arruinaron, mi mente también se arruinó. No sé por qué, no sé si por las presencias de estos seres. No traje leña esa vez, no traje leña, me olvidé la leña, mi hacha y mi machete. Después lloraba toda la noche. Me iba con un tipo que también tenía problemas psicológicos. Mucha gente no me quería, decía que yo estaba loco, tenía el pantalón roto, no me bañaba, no me peinaba, lloraba todo el tiempo, no sé por qué lloraba, sentía tristeza.

Por estos años, buscó ayuda en el centro de salud de su barrio y lo derivaron a una psicoanalítica quien lo atendió durante dos sesiones y volcó su descripción de las vivencias de José — ahora un «caso clínico»— en un informe que llegó a mis manos. Por momentos, la terapeuta se refiere a él como alguien con un «cuadro de depresión», con «dejadez activa y autoagresiones explícitas». Sus acciones son referidas como «acting out... en relación a mandatos». Algunas de las interacciones con no-humanos que José sintetiza en la sesión son leídas por ella como «experiencias en relación con el tema de la locura». Finalmente, la terapeuta transcribe las palabras del paciente tras relatar experiencias nocturnas: «Parece que es una pesadilla, pero es cierto» y expresa que José trasmite «una absoluta convicción acerca de la vivencia». La analista continúa mencionando la centralidad de los sueños y, con acierto, expresa que, para él, «no es como si, sino fue así» (énfasis de la terapeuta). En esta misma línea describe un encuentro con un ser no-humano a quien José, en presencia de otros qom, le arrojó una silla. A pesar de que la gente decía que allí no había nadie, la respuesta de su padre fue: «Aunque no había nadie, hay algo». Estas palabras condujeron a la analista a sostener que 
el «reconocimiento paterno fue de ayuda para que la experiencia no segregara como pura locura». Luego de estas dos sesiones, José abandonó las consultas.

En otra etapa de su vida, sus trastornos causados por encuentros con nohumanos continuaron y José vivía entre el sueño y la vigilia indistintamente:

Yo estaba durmiendo en un basural, yo pensaba que estaba dentro de mi casa y me despierto y me doy cuenta de que es un basural. Y una cara me observa, me aparece la oreja primero y después la forma de la cara, pero la cara sin cuerpo. En esa época vivía en el basural solo, mis papás estaban en casa, yo en el basural. Pero yo ya estaba inconsciente, mi cabeza era el problema, sentía una hinchazón en la cabeza y mi cuerpo deformado, todo deformado, sentía que mis venas se hinchaban y me daba miedo, gritaba. Quería suicidarme, porque tenía un dolor tremendo.

Con los años José alternó su vida entre el basural, el barrio y la escuela secundaria. Se alistó como voluntario en el ejército, fue granadero a caballo en Buenos Aires, miembro de la iglesia mormona en Formosa, escolta del presidente Carlos Menem en el avión presidencial durante un viaje a Israel, estuvo en Buenos Aires visitándome y, en esa ocasión, encontró por la calle al espíritu de su padre vestido de blanco y escuchó el canto de Martini en un pájaro que le avisó que esa noche su padre moriría. Al día siguiente viajamos a Formosa para asistir a su entierro.

Tras estas experiencias, en una oportunidad José concluyó que el dueño de la luna lo sometió a pruebas, le envió presencias espirituales, trastornos en la percepción, dolores físicos, le hizo pasar penurias, hambre, confusiones y discriminación. El mismo dueño de la luna fue quien le mandó a pel'ec, a habitantes del campo, al perro sarnoso y a otras tantas entidades que no solo José conoce sino que son parte de las experiencias ontológicas de numerosas personas tobas. En una ocasión, cuando sus presencias lo atormentaban, le contó a un sacerdote católico que una entidad entre humana y no-humana con forma de perro venía hacia él por las noches y lo asustaba. El cura lo instó a ir a la catedral de Formosa para ser curado. Hace pocos días, en una llamada telefónica, me recordó: «Florencia, me fui a la catedral y allí había tres sacerdotes. Me dijeron que me iban a hacer un exorcismo. Parece que salió algo de mi cuerpo. El sacerdote me tiró agua bendita, me senté y cuando me desperté estaba acostado, con cosas blancas y agua a mi alrededor». Tras el exorcismo, los curas le relataron que estaba poseído por Poseidón, un dios egipcio que suele aparecer con forma de perro. A partir de ahí, dice José, dejó de ver al perro nocturno.

Y, de a poco, sobrevino la calma en la vida de José, no solo desaparecieron los tormentos del perro sino que menguaron las presencias. Una tarde, relata él: 
Encontré un cántaro en el monte, con agua, sin fin, rica, algo muy lindo, chiquitito. Tomaba y me sacié. Mi hermano lo quebró, estábamos jugando en el monte. El primer silbido que escuché me dio temor. Mi hermano decía 'este es de pele'c o de huashole'. Era la casa del pele'c donde estuvimos jugando y ese que quebramos era su cántaro y ellos se enojaron porque tomaban de ahí, eso les da el cuerpo que necesitan. A partir de ahí me sentí distinto. No caminaba solo, alguien caminaba detrás de mí. Cuando tomé eso alguien vino. Era mi sombra. Hasta mi sombra me asustó. A lo mejor mi sombra me molesta y no me deja dormir. Pero vino un hombrecito que me aconsejó, me dijo que consiguiera un cántaro. Ese cántaro es especial para mí porque me trajo la felicidad y me siento feliz, ya puedo ser normal... Estaba caminando, yendo al centro, desde el basural. No tenía zapatillas, ni ropa, estaba toda rota mi ropa. Casi me suicidé: me tiré en una represa, y este hombrecito Qasorot me apareció y me dijo: «¿Por qué estás preocupado? El hornero nunca se preocupa, el hornero cuida de su casita y trata de embellecer su casa, para el hornero es bellísima la vida», así me dijo. «El hornero siempre está feliz por más que no tenga brazos fuertes ni mente grande. Vos tenés una mente especial para esta vida, tenés un montón de trabajos que hacer en este mundo. Tu familia te necesita, vos tenés familia, vos no estás solo». «El hornero, aunque esté solo, siempre va a estar cantando, así debo ser yo», pensé. Siempre feliz con lo poquito que tengo. Qasorot me aconsejó un montón. Es una persona no linda, tiene una colita y es panzón, tiene una cabeza grandota, tiene unos bracitos chiquititos, es un poquito feo pero es lindo de corazón. Él es mi amigo hasta ahora. La luna lo mandó para que él me libere de esa maldad, es como una prueba que tuve. La luna me envió esos hombres, personas del monte para que yo pueda conocer el sufrimiento. Me las envió, son sus camaradas. Pruebas para que yo supere. Él desea que yo algún día pueda ayudar a otra gente con ese problema.

La misma luna que le mandó las pruebas es la que le envió la cura y la capacidad de sanar a personas con el mismo malestar. Años más tarde, José recorría el barrio cuidando a niños huérfanos, a perros abandonados y a prostitutas. Él reflexiona del siguiente modo:

Mi corazón ya está libre y mi mundo es lindo... Qasorot me dijo que pinte el cántaro... Yo obedecí y me sané. Volví a mi casa. La casita de Qasorot es como la mitad del mundo. Aquel que tenga problemas y quiera recuperarse, recurre a él. Yo estaba loco y pedí ayuda y nadie me escuchaba. La mitad del mundo es nuestra casa, ahí somos protegidos de noche... La otra mitad es el mundo entero, en donde hay peligro. Si no tuviéramos casa, pele'c se cruzaría con nosotros, todos los seres espirituales que están en el mundo nos cruzarían. Nos traspasarían y nos harían mal. 


\section{EPÍLOGO}

Pel'ec se encuentra en el origen de los trastornos de Pedro y de José. En el primer caso no se abren los caminos para transitar otras relaciones con otros seres no-humanos. Los padres de Pedro optan por la biomedicina, por el evangelismo, por la reclusión en el hogar y el lobisón. Si la causa es este último, quizás su hijo pueda algún día liberarse del trastorno. Algo que los especialistas médicos y los creyentes no lograron. Pedro solo habla con espíritus. Recorre el patio de su casa materna, intenta dormir, llora y sufre en soledad. Su encuentro con pel'ec no hace eco en el universo de los fármacos, ni en aquel de la oración colectiva que acusa de satánica toda manifestación no-humana.

En el caso de José, pele'c es uno de los múltiples existentes que, desde su nacimiento en un hogar chamánico, transita por sus sueños vividos, incide en sus acciones, percepciones, relaciones y vivencias. El mundo de José oscila entre su hogar y el basural, la escuela y el centro de salud, la iglesia mormona, la catedral y el ejército, entre un perro, una psicoanalista, la luna, un cántaro y un exorcismo. $\mathrm{Su}$ visión del perro nocturno sí hizo eco en la lectura cristiana y la solución de los curas (quitar algo de su cuerpo) también hizo eco en José.

Ahora bien, este «caso clínico» no devino en «pura locura». José logró habitar -al igual que el hornero - su mitad del mundo, es decir, un espacio protegido, como aquel con paredes de vidrio de su padre. En él, distante de la otra mitad — del afuera donde se puede ser traspasado y cruzado por no-humanos- vive hoy una «vida normal», aunque una fina línea divisoria separa su calma del potencial tormento que acecha y que, a veces, aflora en sus sueños. Así como Qasorot le enseñó al hornero a hacer su casa y a ser feliz en ella, los animales y los no-humanos le enseñaron, mediante pruebas y encuentros, que él también debe «formar un mundo» y que, en dicho mundo, la cura de cualquier trastorno será garantizada por aquellos mismos que lo pusieron a prueba. Algo que lamentablemente Pedro no experimentó, aún.

\section{REFERENCIAS}

Bonelli, Cristobal (2013). Ontological disorders: Nightmares, psychotropic drugs and evil spirits in southern Chile. Anthropological Theory, 12(4), 407-426. https:// doi.org/10.1177/1463499612469587

Bonelli, Cristobal (2014). What Pehuenche blood does. Hemic feasting, intersubjective participation, and witchcraft in Southern Chile. Hau: Journal of Ethnographic Theory, 4(1), 105-127. https://doi.org/10.14318/hau4.1.004 
Bonhomme, Julien (2009). Les voleurs de sexe. Anthropologie d'une rumeur africaine. París: Seuil.

Devereux, George (1980[1967]). De l'angoisse à la méthode dans les sciences du comportement. París: Flammarion.

Ceriani Cernadas, César (2005). Conflicto sociorreligioso y representaciones simbólicas entre Tobas mormones y evangélicos. Avá, 7, 45-69.

Ceriani Cernadas, César (2011). Evangelio, política y memoria en los Toba (qom) del Chaco argentino. Nuevo Mundo Mundos Nuevos. Recuperado de http://nuevomundo.revues.org/61083 (31 de marzo de 2011).

Ceriani Cernadas, César (2017). Los evangelios chaqueños. Buenos Aires: Ethnographica.

Karsten, Rafael (1932). Indian tribes of the Argentine and Bolivian Chaco. Helsingfors, Societas Scientiarum Fennica, 4, 10-126.

Lozano, Pedro (1941). Descripción corográfica del Gran Chaco Gualamba. Tucumán: Universidad Nacional de Tucumán.

Medrano, Celeste (2018). El lobizón como excusa. Animalidad y humanidad entre indígenas y criollos del Gran Chaco argentino. 18th IUAES (Internacional Union of Anthropological and Ethnological Sciences) World Congress, Florianopolis, Brasil.

Métraux, Alfred (1937). Études d'Ethnographie Toba-Pilagá (Grand Chaco). Anthropos, Revue Internationale d'Ethnologie et de Linguistique, 32, 171-194, 378-401.

Métraux, Alfred (1963[1946]). Ethnography of the Chaco. En J. Steward (ed.), Handbook of South American Indians, 1(2), 197-380. Nueva York: Cooper Square Publishers Inc.

Miller, Elmer (1979). Los tobas argentinos: armonía y disonancia en una sociedad. México, D. F.: Siglo XXI.

Nordenskiöld, Erland (1912). La vie des Indiens dans le Chaco: Amérique du Sud. Revue de Géographie, 6(3), 278.

Palavecino, Enrique (1933). Indios pilagá del río Pilcomayo. Buenos Aires: Imprenta de la Universidad.

Sterpin, Adriana (1993). La chasse aux scalps chez les Nivakle du Gran Chaco. Journal de la Société des Américanistes, 79, 33-66. https://doi.org/10.3406/jsa.1993.1468

Strathern, Marylin (1988). The Gender of the Gift. Berkeley: University of California Press. https://doi.org/10.1525/9780520910713

Tola, Florencia (2009). Les conceptions du corps et de la personne dans un contexte amérindien. Indiens Toba du Gran Chaco sudaméricain. París: L'Harmattan. 
Tola, Florencia (2012). Yo no estoy solo en mi cuerpo. Cuerpos-personas múltiples entre los qom (tobas) del Gran Chaco. Buenos Aires: Biblos/Culturalia.

Tola, Florencia (2013). The materiality of «spiritual presences» and the notion of person in an Amerindian society. En The social life of spirits (pp. 69-92). Chicago: Chicago University Press.

Tola, Florencia (2019). Sorcery-revenge and anti-sorcery. Individuation and dividuality in the Gran Chaco. Social Analysis, 63(2), 81-101. https://doi.org/10.3167/ sa.2019.630205

Viveiros de Castro, Eduardo (2004). Perspectival Anthropology and the Method of Controlled Equivocation. Tipiti: Journal of the Society for the Anthropology of Lowland South America, 2, (1), 3-22.

Viveiros de Castro, Eduardo (2014). Contra-antropología, contra o estado: uma entrevista com Eduardo Viveiros de Castro. Entrevistador: Paulo Bull. Habitus, 12(2), 146-163.

Wagner, Roy (1975). The invention of culture. New Jersey: Prentice-Hall.

Wright, Pablo (1983). Presencia protestante entre los aborígenes del Chaco argentino. Scripta Ethnologica, 7, 73-84.

Wright, Pablo (2002). L'Evangelio: Pentecôtisme indigène dans le Chaco argentin. Social Compass, 49(1), 43-66. https://doi.org/10.1177/0037768602049001005 